\author{
University of Delaware \\ Disaster Research Center
}

PRELIMINARY PAPER

\#56

\title{
THE ASSESSMENT OF COMMUNITY VULNERABILITY TO ACUTE HAZARDOUS MATERIALS INCIDENTS*
}

Tom Gabor and

Terri K. Griffith

*Presented to the Emergency Planning Research Conference, Arnprior, Ontario, January 29-31, 1979. Some of the data in this paper is based on observations made in the ongoing Disaster Research Center study on "Socio-Behavioral Responses to Chemical Hazards." Funds for that study have been provided by Grant \#ENV77-14445 from the Applied Science and Research Applications Directorate of the National Science Foundation (NSF). However, the statements made represent the views of the authors and not necessarily those of NSF. The authors would like to express their gratitude to Quinten Johnson and Kathleen Tierney, of the Disaster Research Center, for their valuable contributions to the final manuscript. 
The problem posed by hanardous chemicals mannfactured, stored and transported in the tuliced States and Canada has been well documented (Federation of American Sorieties for Expe:imental Biology, 1976).1 In the U. S., acute incidents involving hazardous materials in 1977 resulted in 32 deaths and 543 injurles (Johnstone, 1.973). In 1978, the two railroad incidents in Waverly, Tennessee and Youngstown, Flo:ida alone produced 24 deaths, 159 injuries, 3.3 million dollars in property damage and resulted in legal claims amounting to 550 millior dollars (National Transportation Safety Board, 1978). In Candda, the total number of incidents involving hazardous products has been suid to ise in the neighocrhood of five thousand sinnualiy.2

In the U. 3., over 1,000 new chemicals enter the commercial market annually (Brotn, 1970) and, at anv given time, 70,000 trucks carrying hazardous materials $\varepsilon r \in$ on the road. 3 In addition, extensive railroad as well as barge, pipa?iue and air cargo transportation is undertaken in both countries. It has jeen estimated that four billion tons of hazardous materials ore transportsoj annuaily in the U. S. (Materials Transportation Bureau, 1978).

Despite the magnitude of the chemical problem, it hes been found that different sectors of even hignly vulnerahle communities frequently perceive different levels of threat. A preliminary finding of the Disaster Research Cantar's current study of chemieal hazards indicates that public sector emergency-relevant organizations tend to view chemical hazards in their conmunity as posiog a greater threat than do industrial sarety personnel in these cities (Disasser Recearch Center, 1978). Clearly, consensus on the magnitude of the chemical hazard present in a community is a precondition for appropriate preventive and response-related measures.

Sir.ilarly, tinere does not appear to be a simple linear relationship between tine objective risk to which a community is exposed and public awareness of that risk (Quarantelli and Tierney, 1979). First of ail, the perceptions of the public seem to be influenced by the public relations efforts of the industrial community, the media, other influential percons in a community and so on. Also, it appoars that where the objective level af threat is extremely high for a sufficient period of time and the affected population is forced by circunstances to subject itself to that threat, a desensitization process seems to take place. Consequently, an intense level of threat of. long duration may reduce enxiety relating to that threat. This phenomenon has been noted in discussions of disaster subcultures (Wenger and Weller, 1973) and is corroborated by much of the behaviorist (Watson, et al., 1971) and fsychodynamic (Fine, 1973) litaratures. Clearly, public support for community preparedness reots on the extent of its recognition of the objective risk situation.

Iue to the serious nature of the chemical problem in general and the perceptual problems arising among agencies responsible for mobilization for such threats, the objective assessments of risk are invaluable for focusing the problem and removing perceptual impediments. Through such assessments, the sites of hazardous material production and storage and the major transportation routes, constituting the highest risks in a community, can be identified. 


\section{The Mearing and Implications of Risl: and Vulnerability}

The term "risk" has several connotations and will be used here to denote the threat of hazards which chemical agents per se pose for a community, inciependently of community-wide measures or preparations to reduce the probability of an orcurrence or to mitigate the impact of an incident already underway. The term "vulnerability", on the other hand, will be used here to indicate the status of a community as a totality. Vulnerability, therefore, will zefer to the threat to which a community is exposed taking into account not only the properties of the chemical agents involved but also, the ecological situation of the community and the general state of emergency preparedness at any given point in time.

In the case of natural disasters, one can easily distinguish between the threstering agents themselves (earthquakes, hurxicanes, etc.) and community!dred initiatives with respect to hazard mitigation. Howevex, where hazardous .nterials incidents are concerned, an inextricable relationship exists between the role of the chemical substances involved and the preventive measures employed (or lack thereof). This is due to the fact that such problems are technological by definition, being regarded as preventable due to the human errors necessarily involved at some level. This vould imply that the notions of "risk" and "vulnerability" could not be empirically separated since complex interactions occur between the physical agents, technological processes and safety-related efforts during a hazardous materials episode. This distinction has nevertheless been made as it serves to illustrate the different strategies comiunity planners can pursue according to the relative importance of the two sets of factors in a given situation.

The first observation that can be made on the basis of this conceptral distinction is that community planners should generally concern themselves with the question of vulnerability as this refers to a community's overall sensitivity given the existing level of threat and its coping ability. In extreme cases, however, the risk posed by chemical agents are so severe as to virtually neutralize community planning efforts given the numerous sources of hazards and the potential magnitude of incidents in these communities. In ouril cases, the focus of planners should primarily concern the risk factor (tine hazardous products themselves) and the prevention of such a threat, rether than upon comnunity-related coping measures. This may involve, for apie, an increased regulation of industry and, possibly, the modification of i alustrial processes themselves. Conversely, the level of community preparedness may be so high that an extreme risk factor would nevertheless leave overall vulnerability at a low level. Therefore, if zoning laws exist and industrial facilities are separated from populated areas by industrial parks, if the community-wide emergency response capability is optimal and so on, then the presence of high volumes of high-risk substances will, to a great extent, be nullified.

Figure 1 illustrates the four basic combinations of risk and community reperedness subsumed under vulnerability analysis. 
COMMUNITY VULNERABILITY

PREPAREDNESS

High Low

High Moderately High High

(wide range)

KISK

(UAZARD)

Low Low Moderately Low

(wide range)

Figure 1

The implications of the first cell, where both risk and preparedness are high, have been discussed. Generally, given realistic budgets for communty preparedness, a moderately high level of vulnerability would result. In this case, a balanced emphasis on the agent and emergency response capability could be pursued by community planners. In the situation where the risk factor is high and preparedness low (Cel1 2), vulnerability, clearly, is high. This vulneratility level can be reduced by either lowering the risk factor or improving community preparedness. However, communities of this type are frequently iharacterized by industrial domination of commity political life and resisrance to changes in industrial processes or community preparedness (which may be an admission of industrial hazards) may be anticipated. ${ }^{4}$

Where the risk factor is low and preparedness high, the resultant vulnersbility is low (Cell 3). This situation, which is exemplified by some affluent comiunities, results from a combination of strict legislation regarding the hanufacture of chemicals, an advanced state of local planning, modern auto:outes and high response capability (frequently a by-product of other hazards). ${ }^{5}$

In cities where low levels of risk and preparedness prevail, a moderately Low level of vulnerability will generally result (Cell 4). Here again, as in the first case, extreme situations may considerably alter the vulnerability level. An extremely low degree of preparedness (e.g., populated areas located $\therefore$ jacent to chemical plants, a lack of basic resources for the containment of riamical spills, atc.) may pose problems in the case of even minute incidents. similarly, an extremely low level of risk would produce little danger for even a relatively unprepared community. 


\section{Varieties of Risk/Vulnerability Models}

The above faradigm is merely a conceptual representation of basic points ou the vulnerability continuum. In reality, of course, vulnerability is a continuous variable and a community may be located on any of an infinite number of points on the centinuum.

Attempts at more precise determinations of community hazards have been jerformed in diverse ways. Most of these analyses could, according to our criteria, more accurately be termed risk rather than vulneiability assessmerts. They priciominantly focus on the characteristics of the chemicals involved, rrevailing moteorological conditions and, as far as community-related variables are concerned, tend to iake into account only population related dat.- the population density of a community and the proximity of high risk itites to population centars.

Analyses have been performed to assess the stacus of site and communities boil piior to (Wiggins, 1974; Zajic and Himmelman, 1978) and following (Jack Fnucete Associates, 1970) disasters. Whereas the functions of the former are obvious, post-disaster anelyses have focused on the manner in which organizational recovery operations affect the eventual outcome of an incident and, hence, the general vuinerability of a community. The most prevalent form of risk assessment, however, has been those undertaken in an ongoing emergency sicuation to p:edict the outcome of an incident. The v. S. Coast Guard marine spill system is an example of this type (Environmental Control Inc., 1975). In addition: risk models are varied in complexity, data input and in their purposes ranging from a specific analysis of a single mode (i.e., iransportatico. manufacture, str.raga) to, ds mantioned, the assessment of an entire comnunity.

The data used to formulate a risk model may be ontained from a data base conpiled fiom previous incidents (Jones, 1973) or tinrough the computer simula" tion of events as they are expected to occur given a theoretical framework and tine spentfic:ations of the incident simulated (Silvestro and Mazurowski, 1978). the phenomena to which risk or vulnerability assessments have been applied ranga from a specific site as in the analysis used for determining building satery levels in earthquake-prone areas (Wiggins, 1974); to routes used for :Le tzansportaticn or hazardous commodities as in the Simnons et al. (1974) rinatys is of the ralative risks incurred by various cormunities alongside a seilroad; and: finally, to the pre-disaster assessment of an entire community as in the Zajiz and Himmeiman (1978) comprehensive community vulnerability inodel. Also, as Benner (I977) hes noted, risl analyse have been used for iand use guidance as evidence in iicigation and for environmental impact assessmerits.

The innumerable forms and functions of risk or vulnerajility analyses aze, therefore, evident. The primary concern of this paper is the implications for disaster plannirg posed by the nanufacture. storage and transportation of nazcrdous materials. The subsequent discussion, consequently, involves only those techniques developed to assess the vulnerability of popula-. ted areas which are sites for hazardous chemicel production, storage and/or 
transportation. Policy planners, whether on the state (provincial) or local levels, must not only be informed of existing risks to comonities but also the response-related capability (including resources) already present in those communities if equitable levels of vulnerability are to exist in a region.

One of the few true vulnerability assessment techniques is Zajic and Himmelman's community rating system (1978) which attempts a reconciliation of threat-related factors with a community's ability to cope with such threats. Their index arrives at a maximum disaster rating for a community taking into account the extent of manufacture, storage and highway, rail, marine and pipeline transportation of hazardous chemicals; the hazard classification of the chemicals involved in each case; the population densities gursconding each chemical complex or transportation route and the hazard level of each route. In addition, the authors provide a series of standard criteria to ascertain the degree of community emergency preparedness.

The objective here is not to provide a substantive critique of this s:eting system but, rather, to raise several points regarding its application. Toward this end, the authors have stated the following: "There is a need for various municipalities to be able to assess the hazards that exist in any community with regard to exposure to hazardous materials" (Zajic and Himmelman, 1978: 143). It is difficult to dikcarn from this statement whether the authors recommend the application of their rating scheme to entire municipalities or to specific localities within larger metropolitan areas. Notwithstanding this ambiguity and despite the aforementioned merits of their system, the system may be too specific for a large scale regional assessment and not sufficiently comprehensive for the assessment of a more focalized geographic axea. If a large metropolis is to be assessed, the scheme is too cumbersome with respect to the resources generally available to city officials as it rei.is heavily on visual counting and other observational procedures. The appiication of the system on such a scale would be prohibitively expensive giver. budgetary constraints. On the other hand, if the scheme is to be applied to communities of more manageable size for which highly specific determinations of vulnerability are desired, then this model appears to be at too high a level of generality. As an example, in their determination of a hazard rating for aitoroutes, the only factor taken into consideration is the presence or absence of a median. Admittedly, this has been recognized as a crucial factor; however, wurous other factors should be considered to capture the construct adequately Tihiberg and Tharp, 1968).

\section{An Additional Function of Vulnerability Models}

Vulnerability assessments are needed for at least two levels of use.

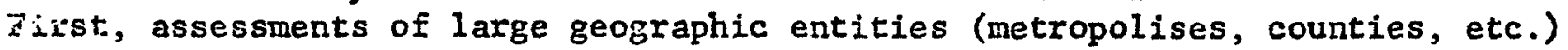
should be ferformed within larger political jurisdictions which have input into local disaster planning (e.g., states or provinces). The distribution of ratings within a state or province can serve as a guideline for the development of policies regarding acceptable levels of vulnerability taking into accornt the resources of that state or province. Such assessments would deterinine the relative sensitivity of different regions providing a rational basis 
for the allocation of rescurces to the localities. Sucin analyses would also identify particularly vulnerabje areas where more focused, localized assessments would be warranted. Areas needing these more specific vulnerability analyses could then obtain the funding to perform the costly data collection procedures involved. The haphazard application of comprehensive assessment techniques in large areas ensures both increased expenditures for state or provincial residents and the assessment of only those communities that can afford them.

Whereas the objective of more general assessments is to provide state or provincial authorities a rough idea of regional differences, the goal of more thorough analyses should be to identify highly sensitive neighborhoods with impications for legislation, emergency response and so on. It is of limited utility for city planners to indicate that city $X$ is highly vulnerable to chemical emergencies. In most cases, the production and transportation of hazardous materials are not evenly distributed throughout a city. High risk azeas must be identified as substantial variaticns may exist among city districts. Zones for analysis should be selected on the basis of their accessability to emergency-related resources, the locus of formulation of disaster ylans, political jurisdictions and on the basis of the manner in which environmental manipulations (the rexouting of hazardous material traffic, the deployment of emergency response personnel, etc.) can be undertaken. In short, communities selected for assessment should be relevant to ecological realities and the manner in which resources are distributed in a region. It is of little use, therefore, to select for ussessment a neighborhood where, geographically. fev environmental modifications can be made and which is serviced by emergencyrelevant agencies based outside of its boundaries. In such cases, the area to be assessed should be extended to one which is a relatively self-contained unit but which, nevertheless, is sufficiently confined to reuder comprehensive analyses relevant.

Assessments of the more general type should conprise basic factors which would provide sufficient differentiation between cities with the ratings obcained being of relevance to planners. Zajic and Himmelman have arrived at five-digit figures such as the 11,134 point rating for one intario city. The practitioner cannot readily ascertain whether a significant difference exists between that figure and. say, ratings of 10,500 or 9,000 or 14,000 . No guidelines for the interpretation of the ratings were provided. In this case, can one assume that the differences between ratings are proportional? In other words, if one city obtains a zating of 10,000 and another of 9,000 then is the first ten percent more vulnerable than the second? This cannot be claimed due to the nature of the computations involved in their system and due to the fact that their index is not a ratio scale--no absolute zero value exists.

For the more general assessments, simple scales can be constructed from which different ratings would have clear, policy-ielaced relevance. The factors should be so basic as to proviáe identical ratings for cities of similar statue. The objective, therefore, would be to classify cities or counties within a larger jurisdiction attempting to mininize the number of categories and to maximize the difference between them. Such siuple rating schemes could be essily applied and, hence, met by less resistance from local officials. The application of such schemes vould serve to acquaint these officials with 
local hazards and their comparative standing in relation to other communities and could influence their general policies with reference to industrial regulation, zoning laws and so on.

\section{A Preliminary Proposal for Large-Scale Assessments}

Some of the recurring factors used in community ratings include the number of chemical plants and storage facilities in a given area, the proximity of these to population centers, the modes of hazardous material transportation used in a city and the types of chemical threat to which the community is exposed. On the basis of these factors, a $0-10$ point scale can be constructed with different weights being given factors of varying importance. Such a scale, if it is to remain relatively simple, can be based on nominal or ordinal level measurement depending upon the number of groups or categories of cities desired. An additive model can be used for simplicity.

The first factor could involve the density of manufacturing and storage facilities in a community. As the term density suggests, this would not comprise a mere absolute counting of facilities within a specified area as has been done in the past. Consideration would be given to the total 1 and area of the region assessed. As the computation of the total acreage of land used by production and storage facilities would be irksome defeating the purpose of the scheme, one can select the total number of employees engaged in production and other blue collar work in such facilities as a reasonable indication of their size. Such data is collected routinely by Chambers of Commerce and various federal agencies. The resulting figure could then be divided by the size (in square miles) of the area assessed. At this point, the figure obtained could either be placed in a high or low density category providing a rating of one point to a commuity in the first category and a zero rating for a community in the second. Or, if ordinal measurement was desired, five levels of density, for example, could be established a priori providing a city in the lowest density category with a zero rating, one in the next with a .25 rating, one in the next with a .50 rating, one in the next with a .75 rating and a city in the highest category would obtain a 1.0 rating.

The density factor would probe both the likelihood of an incident originating from a community and the probability that such an incident would impact the population therein. Impact, as $1 t$ is used here, refers to the economic as well as the physical harm inflicted upon the community. The density figure also incorporates (because of its consideration of plant size) the volumes dealt with by chemical facilities and, hence, the potential magnitude of an incident.

The second factor that could be employed in the rating scheme is the general proximity of production and storage facilities to residential and commercial areas. This factor is also concerned with the likelihood of an incident's direct physical impact upon a community. Although this factor appears to be closely related to the first, the density factor frequently does not probe proximity. Where industrial plants are clustered in one section of a city, the overall density figure for the city may be high (if such plants are numerous and/or large) although few, if any, may threaten the general community. On the 
other hand, another community may possess the same density of facilities; however, these may be diffuse threatening various localities.

Proximity san be calculated by using as a standard a distance which would be considered as safe from flying debris and tremors caused by plant explosions involving volatile substances. One can select the figure of 2,000 feet claimed by the National Fire Prevention Association in the $U$. $S$. to be safe (free of fatalities) in 99\% of explosions (U. S. Department of Transportation, 1978). As toxic fumes may disperse considerably in excess of this 2,000 foot radius, the nature of the chemical substance(s) dealt with, in addition to prevailing wind currents and other factors, may warrant the modification of this criterion. Through simple mapping, one can compute the percentage of facilities located within the prescribed distance from residential or commercial areas. One could egain arrive at a high or low proximity determination or ordinally categorize the proximity of a city as extremely low to extremely high. The maximum rating for this factor would also be one point.

Next, the transportation factor would have three constituents. Since hazardous chemicals are primarily shipped by road, rail or baxge, the deterwination of whether a community is traversed by such routes is crucial. If a simple nomingl scheme was used, an affirmative answer in each case nould yield a one point rating for each type (of the three mentioned) of major route that crosses or bypasses a city. Or, through more detailed observation, one could determine the mileage of such routes in a city and then rate the city depending upon the extent of each mode of transportation from a minimum of zero to a maximum of one point.

The transportation threat is provided greater weight on the ten-point scale (three points) than are the threats produced by manufacturing and storage for two reasons. First, transportation incidents are the most frequent. Second, since vulnerability is of interest here, transportation incidents through their complexity complicate the tesks of emergency preparedness and response. Such incidents may occur at a multiplicity of locations in a city; the identification of spilled chemicals is more difficult; resources for the neutralization of the chemicals are not as readily available; and the incidents are frequently interjurisdictional : introducing problens involving the coordination of response."

While the first three factors dealt with the different sources of hazard in a community (production, storage and transportation), a fourth factor can concern itself with the types of threat to which a commuity is exposed. This assentially refers to the types of chemicals produced, stored and transported. Forms of hazard include fire or conflagration, explosions (vibrations and flyiug fragments), toxic releases (air or water) and damage tinrough sudden. corrosion. Each of these five threats, if present on a major scale, could be provided a one point rating. Therefore, this fourth factor (dealing with the quality of the hazard) would have a total weight of five points which is equivglent to the weight of the first three factors (which dealt with the likelihood and potential magnitude of hazards of differing sources). A ten-point "risk" scale would then be complete.

If a vulnerability index is desired, bearing in mind that vulnerability here is regarded as a combination (product) of risk and commuity preparedness, 
a ten-point scale to determine preparedness must be devised. Such a scale could rate a commity on the basis of the presence of an overall disaster plan, emergency procedures for major manufacturers, a local mutual aid system for resource sharing, physical resources and expertise to counteract the variety of thrests existing in the community, community-wide disaster drills and so on. The resultant rating on this ten-point scale could then be multiplied by the city's score on the initial ten-point risk scale. The denominator and numerator of the resulting figure can each be divided by ten to obtain the city's final rating on a ten-point scale. The entire procedure is summarized in Figure 2.

\section{REGIONAL VULNERABILITY SCALE}

\section{FACTOR}

Density

Proximity

Transportation - a) Road

b) Rail

c) Barge

Forms of Threat - a) Major Fire

b) Explosion

c) Toxic Release (Air)

d) Toxic Release (Water)

e) Acute Corrosion
MAXIMUM WEIGHT

(Points)

1

1

1

1

1

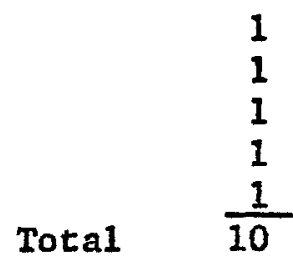

Figure 2 


\section{SUMMARY}

The manufacture, storage and transportation of voluminous quantities of hazardous chemicals in the United States and Canada pose serious problems for local and regional planners. Part of the problem stems from the lack of recognition of these hazards by community personnel most responsible for their mitigation. The identification of these hazards through risk assessments can thus serve to provide objective confirmation of their existence and can outline the specifications of the problem.

Emergency planners, however, should not merely concern themselves with the physical hazard, "risk", that confronts them. In developing disaster mitigation strategies, both on the local and regional levels, planners should also take into account the existing state of preparedness of the assessed area, "vulnerability." For the local planner, knowledge of his community's response capability will indicate the extent to which local hazards pose a genuine danger and whether additional resources should be acquired and mobilized. This information also enables local policy-makers to decide whether to increase industrial regulation or to upgrade the extant level of preparedness. For regional planners, vulnerability assessments indicate the needs and resources of localities within their jurisdiction permitting the formulation of policies on rational grounds and the equitable allocation of resources. Furthermore, such regional assessments can identify the most sensitive localities where more precise hazard assessments can be performed.

These more specific analyses should isolate particularly vulnerable neighborhoods and should be applied to areas where emergency-related resources can be clearly identified. Regional evaluations, on the other hand, should consist of more basic vulnerability indicators for which data can be facilely obtained. For both types of schemes, the final rating obtained should have relevance for emergency planning.

A regional vulnerability scale should consist of two components. First, a hazard assessment component where such factors as the density of chemical production and storage facilities in the community, their proximity to populated areas, the various modes of hazardous material transportation and the different forms of chemical threat are considered. The second component can comprise a checklist of activities to be performed for optimal emergency preparedness and the extent to which such activities are undertaken in a particular community. 
1. T. Gabor, "Chemical Hazards." Paper presented at the Senior Officer's Training Seminar of Emergency Planning Canada, September 1978, Arnprior, Ontario.

2. Personal communication with Comnander H. Beach, Environment Canada, December, 1977.

3. ABC Evening News. July 31, 1978.

4. Observations by field workers.

5. Ibid.

6. Ibid. 


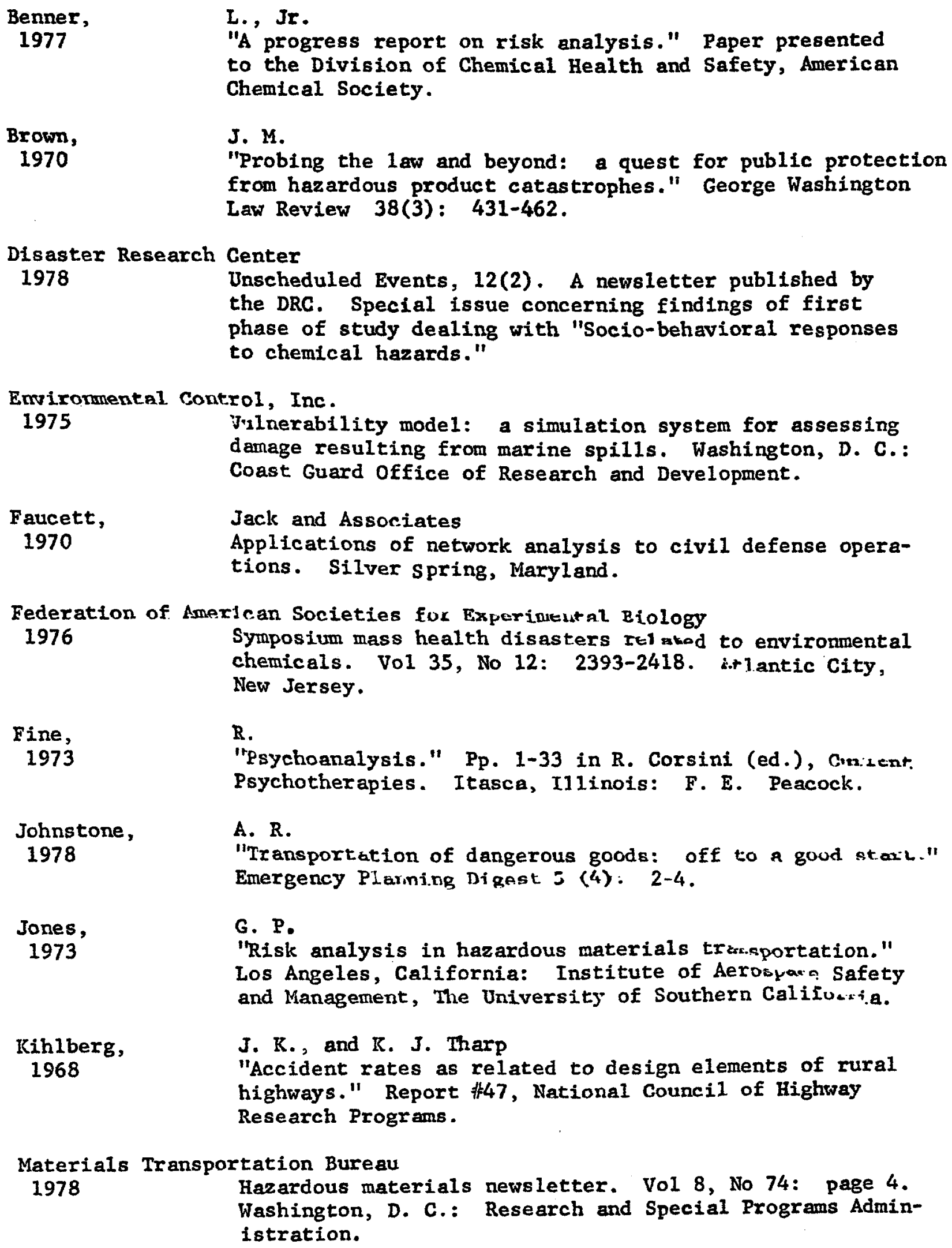

Hazardous materials newsletter. Vol 8, No 74: page 4 . Washington, D. C.: Research and Special Programs Administration. 


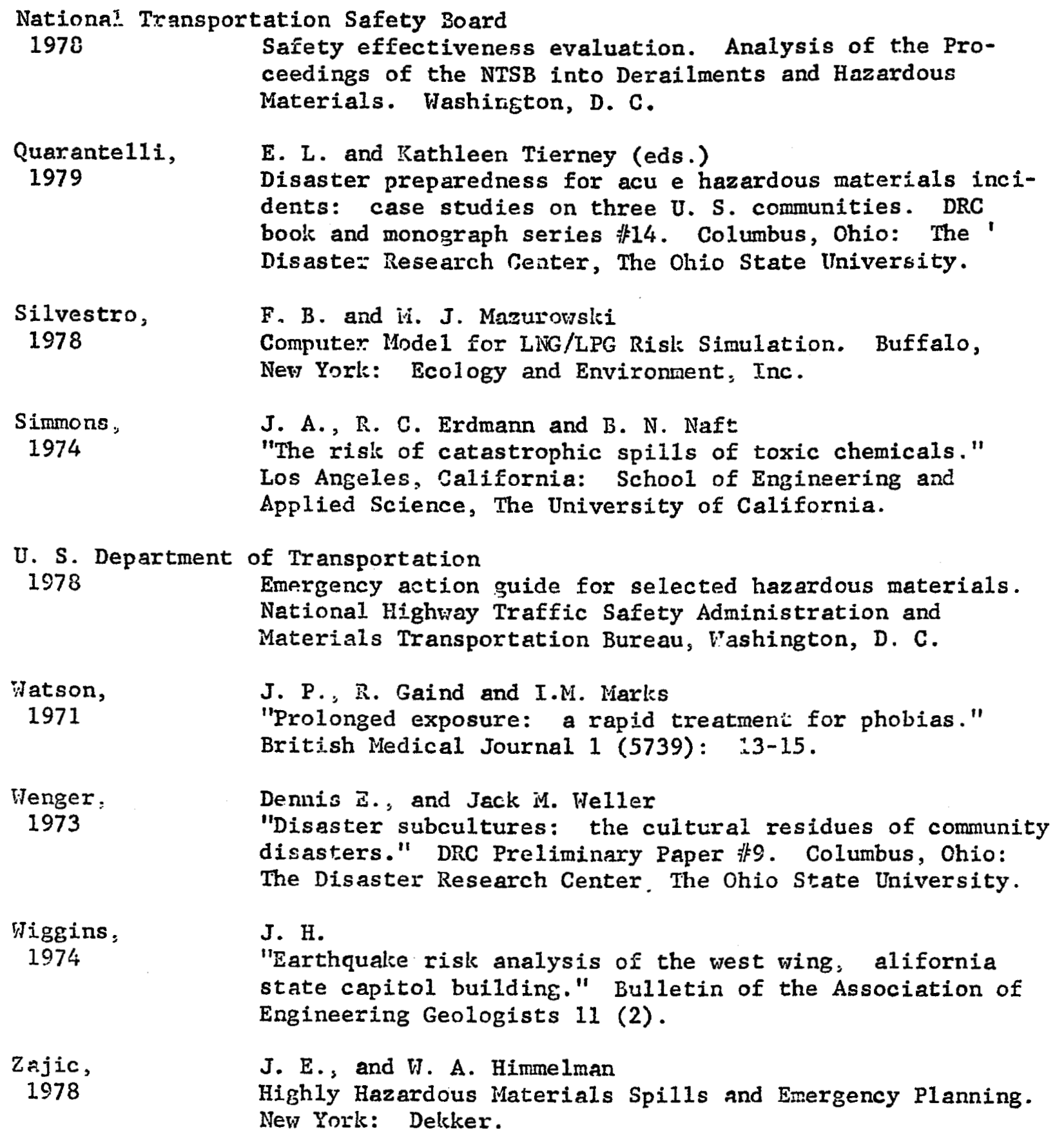


Unclassified

Security Classification

\section{DOCUMENT CONTROL DATA - R \& D}

(Security classification of titte, body of abstract and indexind annotation must be ontered when the overall report is classtiflod) 1. ORIGINATING ACTIVITY (Corporate buthor)

Disaster Research Center

Department of Sociology

The ohio state University

Gêmbits obio 43210

20. AEPORT SECURITY CLASSIFICATION Unclassified

INITIAL OBSERVATIONS ON PROBLEMS AND DIFFICULTIES IN THE USE OF LOCAL EOCS IN NATURAI, DISASTERS

4. OESCRIP TIVE NOTES (Typo of report and inclualve dintes)

One of a series

5. AUTHOR(S) (FIrat name, middlo InIIIA, last nama)

E. L. Quarante11i

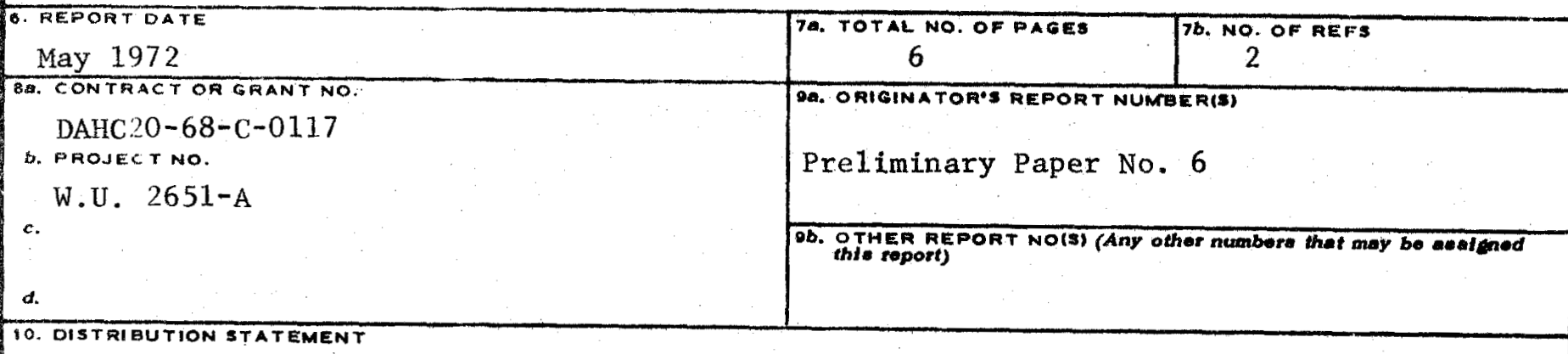

APPROVED FOR PUBLIC RELEASE; DISTRIBUTION UNLIMITED

11. SUPPLEMENTARY NOTES

2. SPONSORING MILITARY ACTIVITY

Defense Civil Preparedness Agency

Washington, D.C. 20301

An initial examination was made of the use of emergency operations centers (Eocs) in natural disasters in American society in the last eight years. Problem areas were noted in participation in EOCs, tasks carried out at EOCs, the location of EOCs, and the time of activation of EOCs. But despite problem areas, EOCs were found to be of value and important in a response to community emergencies. 
Unclassified

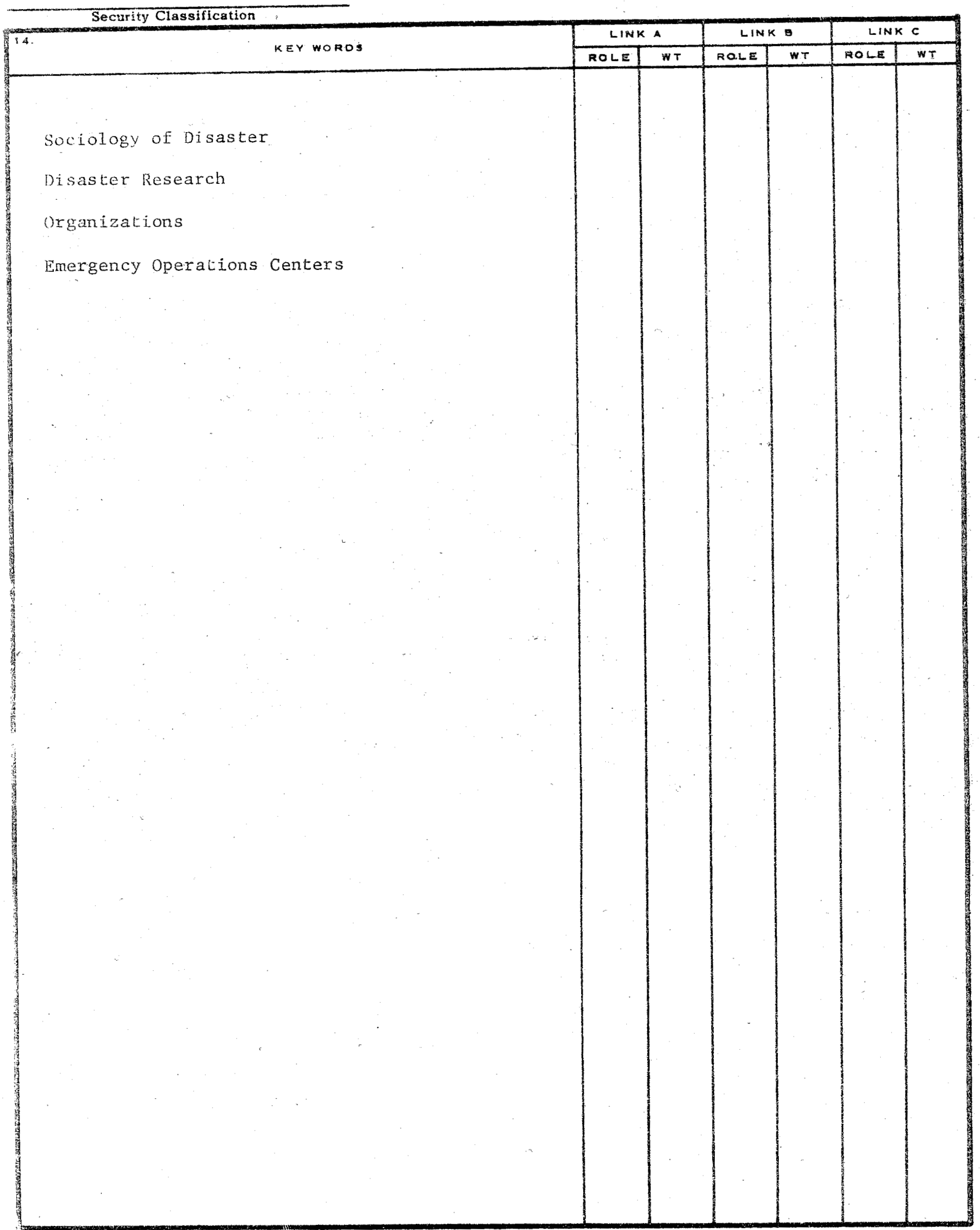

Unclassified 